\title{
Prevalence and factors associated with hypertension in primary school children, in the centre region of Cameroon
}

\author{
David Chelo, Evelyn M. Mah, Edmond N. Chiabi, Andreas Chiabi, Paul Olivier Koki Ndombo, \\ Samuel Kingue, Marie Therese Obama \\ Faculty of Medicine and Biomedical Sciences, University of Yaounde I, Yaounde, Cameroon \\ Contributions: (I) Conception and design: D Chelo, EN Chiabi, EM Mah; (II) Administrative support: MT Obama, A Chiabi; (III) Provision of study \\ materials or patients: A Chiabi, MT Obama; (IV) Collection and assembly of data: EN Chiabi; (V) Data analysis and interpretation: EN Chiabi, D \\ Chelo, EM Mah, S Kingue; (VI) Manuscript writing: All authors; (VII) Final approval of manuscript: All authors. \\ Correspondence to: Edmond N. Chiabi. Faculty of Medicine and Biomedical Sciences, University of Yaounde I, Yaounde, Cameroon. Email: \\ edmondchiabi@gmail.com.
}

Background: There has been a progressive increase in hypertension among children and adolescents over the years. Hypertension in childhood is influenced by various risk factors including; childhood obesity, lifestyle and hereditary factors. This study is aimed at assessing the prevalence of hypertension and elevated blood pressure (BP); as well as the associated factors to hypertension among primary school children in a rural setting in the, Centre Region of Cameroon.

Methods: A cross sectional study was carried out from November 2017 to May 2018 in 13 primary schools in Mbankomo subdivision. A two staged cluster sampling technique was used to select participants: the first stage we conveniently selected 13 out of 71 (18\%) primary schools in the study area by probability proportionate to size since the subdivision does not have an equal number of primary schools in the rural and semi-urban areas. In the second stage, we also used probability proportional to size to randomly select participants from the 13 clusters because the classes did not have equal number of students. We randomly selected $13 \%$ pupils enrolled in each class of the 13 schools. BP and anthropometric measurements were taken, together with socio-demographic characteristics, lifestyle and past history.

Results: The overall prevalence of hypertension among the 822 pupils sampled was $1.6 \%$ (with $1.5 \%$ in stage I and $0.1 \%$ in stage II) and that of elevated BP was $8.1 \%$, with a systolic predominance of $1.6 \%$. SBP and DBP had a significant positive correlation with age $(r=0.17 ; \mathrm{P}=0.000$ and $\mathrm{r}=0.07 ; \mathrm{P}=0.000$ respectively) and $\mathrm{BMI}$ ( $\mathrm{r}=0.18 ; \mathrm{P}=0.000$ and $\mathrm{r}=0.11 ; \mathrm{P}=0.000$ respectively). The associated risk factors for hypertension were: the pupil's age $>10$ years (95\% CI: 1.2581-33.1841; $\mathrm{P}=0.0254)$, family history of overweight (95\% CI: 1.6906-32.9401; $\mathrm{P}=0.008$ ), and excess weight (95\% CI: 2.5094-40.7063; $\mathrm{P}=0.0011$ ), and being born at term $(\mathrm{P}=0.0004)$ as a protecting factor.

Conclusions: This study revealed a high prevalence of hypertension among primary school children in rural areas, with a number of preventable risk factors. Considering the risk factors found, children should be educated on proper nutrition, and the need for physical exercises at home and in school to avoid overweight and obesity.

Keywords: Hypertension; associated factors; pupils; rural area; Cameroon

Submitted Jan 21, 2019. Accepted for publication Mar 29, 2019.

doi: $10.21037 /$ tp. 2019.03 .02

View this article at: http://dx.doi.org/10.21037/tp.2019.03.02 


\section{Introduction}

WHO estimates that, approximately $40 \%$ of adults aged 25 suffer from hypertension; the number of people with the condition rose from 600 million in 1980 to 1 billion in $2008(1,2)$. In children, the prevalence as reported by various studies, ranges from $5.4 \%$ to $19.4 \%$ (3-7) with an increase in trends in the last two decades.

The National High Blood Pressure Education Program Working Group (NHBPEP) defines hypertension in children as either systolic and/or diastolic blood pressure (BP) $\geq 95^{\text {th }}$ percentile measured on three or more occasions (8). The implications of hypertension in children are medical sequelae some of which persist into adulthood when undiagnosed; death and cardiovascular disability due to target organ damage (9). Renal parenchymal disease and renovascular diseases account for most cases of secondary hypertension predominant in children and adolescents as compared to adults (10).

According to the Task Force recommendations on BP control in children, every child aged 3 years and above should have his/her BP measured on every healthy/sick visit. This will lead to early diagnosis and identification of those at risk is an important strategy for public health control and prevention of cardiovascular diseases (8).

In Africa several studies indicated prevalences varying from 4.7-23.2\% (11-13). In Cameroon, studies carried out in some urban areas (Bertoua, Yaounde and Buea) revealed that the prevalence among school children varied between $2.2-3.2 \%$, and were strongly associated to overweight (14-16).

We thus decided to undertake this study, in Mbankomo, a rural area near Yaounde in the Centre Region of Cameroon, in order to assess the trends of high BP in school children and the factors influencing its occurrence in this setting.

\section{Methods}

\section{Study population and design}

The study is a cross-sectional analytic study carried out over a period of 6 months (from $21^{\text {th }}$ November 2017 to $22^{\text {th }}$ May 2018) in public and private primary schools in the Mbankomo subdivision, in the Mefou and Akono division, in the centre region of Cameroon.

\section{Study setting}

Mbankomo subdivision is situated $25 \mathrm{~km}$ South West of
Yaounde. It has a population of 20,305 inhabitants and a surface area of $1,300 \mathrm{~km}^{2}(17)$.

\section{Sampling and procedure}

Of the 71 primary schools with a total population of 10,308 pupils, 13 were randomly selected by probability proportionate to size. Then in the second stage, we used probability proportionate to size to randomly select $13 \%$ participants from each class since the number of pupils enrolled in each of the 13 schools selected above was different. Using the Cochran's formula (18) and the prevalence of 3.2\% found in Samain Nkendo's study in Buea (16), the minimal sample size was 328 pupils.

The selected pupils had a verbal and a written signed consent from parents/guardians before inclusion in the study.

The primary school children enrolled in the study, had to be present in school, with the signed consent form by parents or tutors, and who accepted to participate in the study. The study excluded any child who had any disability not permitting weight, height, or BP taking as recommended by the $\mathrm{WHO}$, and those taking medications known to lower BP in whom a diagnosis of hypertension has not been made.

The variables noted included: socio-demographic characteristics of the child (age, sex, type of school, class, school setting, profession of legal tutor), lifestyle (feeding habits, physical activities), medical records of the child (birth weight, term, chronic illness), medical history of the parents and other family members (family history of hypertension, obesity or overweight, diabetes), anthropometrics (height, weight, BMI) and BP measurements.

The questionnaires were distributed to the pupils for the parents/guardians to fill at home. The next day, BP and anthropometric measurements were taken, and repeated once a week for 2 weeks.

\section{BP measurements}

Before BP measurements taken, pupils were familiarized with the instrument and the nature of the procedure explained. BP was measured in the sitting position, on the right arm, using the auscultatory method with a pediatric stethoscope, and a standard aneroid sphygmomanometer $\left(\right.$ GIMA $\left.^{*}\right)$ with appropriate cuff size covering at least $2 / 3^{\text {rd }}$ $(67 \%)$ of the upper arm and encircling it completely. The child's right arm was supported at the level of the heart 
during measurements. This was the preferred arm because of consistency and comparison to standard tables and also because of the probability of decreased BP on the left arm caused by coarctation of the aorta (8).

The stethoscope was placed lightly over the brachial artery. The cuff was inflated to a pressure of $30 \mathrm{mmHg}$ above the level at which the radial pulse was no longer palpable. While slowly deflating the cuff, the Korotkoff phase I was listened while watching the BP gauge. Korotkoff phase I was identified by the first pulse auscultated. The measurement was then recorded from the sphygmomanometer at which the sound first appeared; representing the participant's systolic BP. While watching the sphygmomanometer, the cuff was continuously slowly deflated till an abrupt soft, indistinct, muffling sound was heard (Korotkoff phase IV). This sound was then continuously listened until it disappeared completely (Korotkoff phase V) and recorded; this represented the participant's diastolic BP. The cuff was completely deflated and the child was allowed to rest.

For each participant, BP was measured twice in the same visit with a minimum of 30 seconds rest interval and the mean BP calculated. We waited for another 1-2 minutes and repeated the BP measurement procedure on the participant's opposite arm and if a measurement discrepancy existed between the 2 arms, the arm with the highest measurement was noted. BP readings were taken to the nearest $2 \mathrm{mmHg}$. BP readings were classified according to the recommendations of AAP (19) as follows:

* Elevated BP if SBP and/or DBP were between $90^{\text {th }}$ and $95^{\text {th }}$ percentile for age, height and sex or if SBP $>120 \mathrm{mmHg}$ or DBP > $80 \mathrm{mmHg}$.

* Hypertensive if SBP and/or DBP were equal to or greater than the $95^{\text {th }}$ percentile for height, age and sex.

Participants were considered hypertensive if the BP remained elevated after 3 weekly measures.

\section{Anthropometric measurements}

The pupils were weighed barefoot, standing still, without support and wearing light clothes, using a manual weighing scale $\left(\mathrm{Seca}^{*}\right)$ and recorded to the nearest $0.1 \mathrm{~kg}$. Height was measured using a wooden stadiometer (UNICEF*) calibrated in centimeters $(\mathrm{cm})$ and recorded to the nearest $0.1 \mathrm{~cm}$

Each participant stood erect with no shoes on and with the occiput, shoulder, buttocks and calf touching the vertical position of the stadiometer. Were considered obese those with $\mathrm{BMI} \geq 95^{\text {th }}$ percentile, overweight $\geq 85^{\text {th }}$ and $<95^{\text {th }}$ percentile, normal with $\geq 5^{\text {th }}$ and $<85^{\text {th }}$ percentile, and underweight those with $\mathrm{BMI}<5^{\text {th }}$ percentile.

\section{Data collection}

Data was collected from filled questionnaires and clinical examinations.

\section{Statistical analysis}

Analysis was done using Epi-Info ${ }^{\mathrm{TM}}$ 3.5.4 and WHO AnthroPlus $^{\mathrm{TM}}$ 1.0.4 softwares. The Chi-square test was used to evaluate the association between qualitative variables and the Pearson correlation test was used to evaluate the association between quantitative variables. The degree of association was assessed using the odds ratio and its confidence interval $(\mathrm{CI})$ at $95 \%$, and statistical significance was considered at a $\mathrm{P}$ value $<0.05$.

\section{Ethical considerations}

After obtaining authorizations from the Divisional Delegation of Basic Education at Ngoumou and the Sub Divisional Inspectorate of Basic Education at Mbankomo in the Mefou and Akono division, an ethical clearance was obtained from the Institutional Review Board of the Faculty of Medicine and Biomedical Sciences and informed consent from parents.

\section{Results}

For this study, 1,754 consent forms and questionnaires were distributed to all the pupils enrolled in the 13 selected primary schools in the study area. We excluded 422 (34\%) pupils who were absent from school on the days BP and anthropometric measurements were taken, poorly filled questionnaires and loss to follow-up. We finally enrolled 822 pupils in the study.

\section{Socio-demographic characteristics of study population}

Of the 822 pupils recruited, 469 (57.1\%) were females and $353(42.9 \%)$ were males, giving a sex ratio of 1.3 . The mean age was $9 \pm 2.5$ years (with extremes from 5 to 17 years). The most represented age range was $8-11$ years $(41.1 \%)$, and $681(82.8 \%)$ pupils were from public schools while 141 $(17.2 \%)$ from private schools. 
Table 1 Socio-demographic characteristics of the study population

\begin{tabular}{|c|c|c|c|}
\hline Variable & \multicolumn{2}{|c|}{ Frequency (n) } & centage (\%) \\
\hline \multicolumn{4}{|l|}{ Gender } \\
\hline Male & \multicolumn{2}{|c|}{353} & 42.9 \\
\hline Female & \multicolumn{2}{|l|}{469} & 57.1 \\
\hline \multicolumn{4}{|l|}{ Age (in years) } \\
\hline $5-8$ & \multicolumn{2}{|c|}{268} & 32.6 \\
\hline $8-11$ & \multicolumn{2}{|l|}{338} & 41.1 \\
\hline $11-14$ & \multicolumn{2}{|l|}{193} & 23.5 \\
\hline $14-17$ & \multicolumn{2}{|c|}{23} & 2.8 \\
\hline \multicolumn{4}{|l|}{ Type of school } \\
\hline Public & \multicolumn{2}{|c|}{681} & 82.8 \\
\hline Private & \multicolumn{2}{|l|}{141} & 17.2 \\
\hline \multicolumn{4}{|c|}{ Profession of legal tutor } \\
\hline Non liberal ${ }^{*}$ & \multicolumn{2}{|l|}{139} & 16.9 \\
\hline Liberal $^{\star \star}$ & \multicolumn{2}{|c|}{409} & 49.8 \\
\hline Unemployed & \multicolumn{2}{|c|}{274} & 33.3 \\
\hline \multicolumn{4}{|c|}{$\begin{array}{l}{ }^{*} \text {, civil servants; }{ }^{* *} \text {, lawyers, traders, technicians, workers in the } \\
\text { private sector, students. }\end{array}$} \\
\hline \multicolumn{4}{|c|}{ Table 2 BMI classification of the study subjects } \\
\hline BMI & & $\begin{array}{l}\text { Frequency } \\
\qquad(\mathrm{n})\end{array}$ & $\begin{array}{l}\text { Percentage } \\
\quad(\%)\end{array}$ \\
\hline$\geq 5^{\text {th }}$ and $<85^{\text {th }}$ & nal) & 757 & 92.1 \\
\hline$<5^{\text {th }}$ percentile & & 5 & 0.6 \\
\hline$\geq 85^{\text {th }}$ and $<95^{\text {th }}$ & erweight) & 55 & 6.7 \\
\hline$\geq 95^{\text {th }}$ percentile & & 5 & 0.6 \\
\hline Total & & 822 & 100.0 \\
\hline
\end{tabular}

Most of the legal tutors (49.8\%) were doing liberal professions (Table 1).

\section{Anthropometric parameters of study population}

Most of the pupils, 757 (92.1\%) had a normal body mass index; 55 (6.7\%) pupils were overweight; and $5(0.6 \%)$ pupils were obese (Table 2). Out of the 60 pupils who were overweight/obese, 45 were in the 5-11 years age group, and 37 were females. There was a positive correlation of the

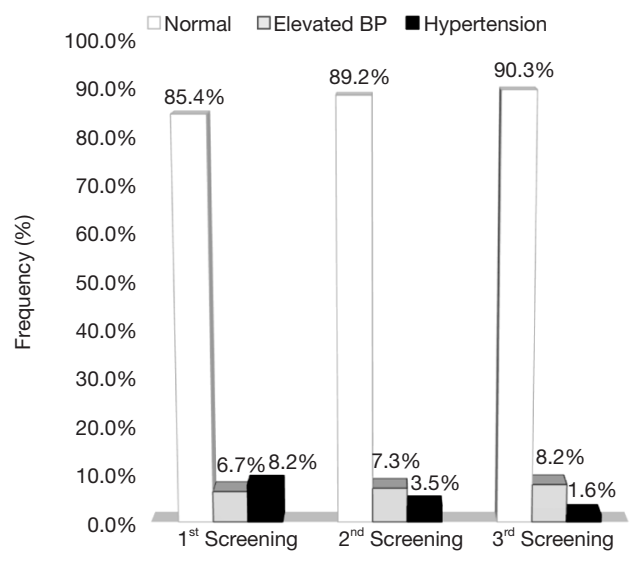

Figure 1 Prevalence of hypertension and elevated BP on all 3 screenings. BP, blood pressure.

Table 3 Prevalence of elevated BP and HTN (N=822)

\begin{tabular}{lcc}
\hline Blood pressure status & Frequency $(\mathrm{n})$ & Percentage (\%) \\
\hline Normal & 742 & 90.3 \\
Elevated BP & 67 & 8.2 \\
Hypertension & 13 & 1.6 \\
Stage 1 & 12 & 1.5 \\
Stage 2 & 1 & 0.1 \\
\hline
\end{tabular}

BP, blood pressure.

BMI with age $(\mathrm{r}=0.256 ; \mathrm{P}<0.0001)$.

\section{Prevalence of elevated BP and bypertension}

Following the first screening, 55 (6.7\%) pupils had elevated BPs and 67 (8.2\%) pupils were found to be hypertensive. On control, 1 week after the first measurement, 60 (7.3\%) pupils had an elevated BP level and 29 (3.5\%) were hypertensive. After the third measurement, 1 week after the second, 67 (8.2\%) pupils had an elevated BP level and 13 (1.6\%) hypertensive (Figure 1).

Out of the 13 (1.6\%) hypertensive pupils, $12(1.5 \%)$ had stage one hypertension, and $1(0.1 \%)$ stage two hypertension (Table 3). The elevated BP and hypertension was predominantly systolic in $67(8.2 \%)$ pupils and in 13 (1.6\%) pupils respectively. The systolic BP $(\mathrm{r}=0.17$; $\mathrm{P}=0.000)$ and the diastolic $\mathrm{BP}(\mathrm{r}=0.07 ; \mathrm{P}=0.000)$ significantly increased with age; and likewise, the systolic $\mathrm{BP}(\mathrm{r}=0.18$; $\mathrm{P}=0.000)$ and the diastolic $\mathrm{BP}(\mathrm{r}=0.11 ; \mathrm{P}=0.000)$ also, 
Table 4 Multivariate analysis with logistic regression

\begin{tabular}{lccc}
\hline Variables & Odds ratio & $95 \% \mathrm{Cl}$ & $\mathrm{P}$ value \\
\hline Age $>10$ years & 6.4614 & $1.2581-33.1841$ & 0.0254 \\
Birth weight $<2,500$ grams & 4.1894 & $0.0575-305.4815$ & 0.5127 \\
At term & 0.0845 & $0.0216-0.3307$ & 0.0004 \\
Prematurity & 1.578 & $0.0216-115.3462$ & 0.835 \\
Recurrent urinary tract infection & 3.7988 & $0.4371-33.0119$ & 0.2263 \\
HTN in family & 1.1318 & $0.2845-4.5025$ & 0.8605 \\
Overweight in family & 7.4624 & $1.6906-32.9401$ & 0.008 \\
Excess weight & 10.1069 & $2.5094-40.7063$ & 0.0011 \\
\hline
\end{tabular}

*, overweight and obesity. $\mathrm{Cl}$, confidence interval.

significantly increased with BMI.

\section{Associated factors}

The independent factors associated with hypertension were, the pupil's age $>10$ years old $(\mathrm{P}=0.0254)$, overweight in family $(\mathrm{P}=0.008)$ and excess weight $(\mathrm{P}=0.0011)$ while being born at term $(\mathrm{P}=0.0004)$ was a protecting factor (Table 4$)$.

\section{Discussion}

The prevalence of hypertension in the study population was $1.6 \%$ of the pupils and, $7.9 \%$ of pupils had an elevated BP level and $92.1 \%$ of the pupils had a normal BP level. The prevalence of hypertension was less than that reported by Fotso in Yaounde in 2012 (15), Bissohong in 2014 in Bertoua (14), Samain in 2015 in Buea (16). Higher figures have equally been reported in other African studies ranging from $3.5 \%$ to $10.8 \%$ (20-22). Again, higher prevalence ranging from $2.7 \%$ to $20.6 \%$ have also been described by other authors around the world $(7,23,24)$. The difference between these prevalence and ours, could be attributed to the fact that the sample sizes were smaller than ours, the studies were carried out in urban settings and the authors used the United States-based 2004 Task Force Report Update and French Reference Criteria which all tend to overestimate the BP.

There was a female predominance $(57.1 \%)$ with a sex ratio of 0.8 . Sadoh $e t$ al. in Nigeria equally noted this female predominance in 2014 (51.1\%) (25). The mean age of the pupils was 9 years with extremes of 5 and 17 years, and the most represented age group was $8-10$ years. This age group is similar to that found by Samain (16), which corresponds to age of children attending primary school in that area.

After multivariate analysis, the independent factors associated with HTN were; the pupil's age $>10$ years old, family history of overweight, and excess weight. On the other hand, being born at term was protective.

Bissohong in 2014 in Bertoua also noted that pupil's age $>10$ years old was associated to hypertension (14) whereas, Kagura et al. in 2015 reported that the majority of hypertensive cases were pre-adolescents and adolescents (26). In Tanzania, Muhihi et al.'s study in 2018, noted that the prevalence of elevated $\mathrm{BP}$ was higher among children aged more than 10 years (22). Age-related increase in BP is partly attributable to increasing weight with age (22).

The family history of overweight was strongly associated to hypertension in our study. Contrary to observations made in Bissohong's study, which showed no statistically significant association (14). According to Kanciruk et al., family history of obesity can be considered to be both environmental and biological in nature (27). In terms of environmental risk, parents, particularly mothers, tend to ingrain their personal eating habits as well as their perceptions of weight to their children and, in terms of its biological nature, the genetic influence of overweight/obesity may predispose children into developing this condition. Obesity is known to be a precursor of cardiovascular diseases and particularly hypertension (27).

We also noted a statistically significant association between excess weight and hypertension. This finding was also observed by Arun et al. (28). The association between excess weight and hypertension could be attributable to over activation of the renin-angiotensin and sympathetic nervous 
systems; insulin resistance; and abnormality in vascular structure and function observed in obese children (29).

Pupils born at term were less likely to be hypertensive. In fact, delivery at term was protective of hypertension. Some studies indicated prematurity as a risk factor for hypertension (30-33). The mechanisms by which BP levels appear to be elevated in children and young adults who were preterm are not fully understood. The possible contributing factors include impaired morphological development of glomeruli and fewer nephrons on the basis of interrupted kidney development resulting in small kidneys, microvascular growth arrest and rarefaction building up peripheral vascular resistance (30). However, the reporting of term and preterm delivery in our study could not be verified because we did not have access to the hospital delivery notes of the pupils from their legal tutors.

\section{Conclusions}

The prevalence of hypertension in this rural setting was lower than that observed in the urban areas of Cameroon. The associated factors for hypertension in this setting as observed in our study were; the pupil's age $>10$ years, family history of overweight and excess weight and being born at term was a protecting factor. We thus recommend that nutrition courses and physical education should be reinforced in the school curricular; that BP monitoring be integrated as part of routine clinical examination during medical visits of healthy and sick children; and that the parents should encourage healthy eating habits at home and in school and, ensure physical activity at home.

\section{Acknowledgments}

Sincere gratitude to the children and parents who accepted to participate in this study.

\section{Footnote}

Conflicts of Interest: The authors have no conflicts of interest to declare.

Ethical Statement: The study was approved by the Institutional Review Board (No. 0042/UY1/FMSB/VDRC/CSD) of the Faculty of Medicine and Biomedical Sciences. Informed written consent was obtained from the parents before data was collected.

\section{References}

1. World Health Organization. Global brief on hypertension [Internet] 2013 [Cited 2017 July 24]. Available online: www.who.int

2. Rahimi K, Emdin CA, MacMahon S. The Epidemiology of Blood Pressure and Its Worldwide Management. Circ Res 2015;116:925-36.

3. Simonetti GD, Bucher BS, Tschumi S. Hypertension chez l'enfant et l'adolescent. Rev Méd Suisse 2011;7:1041-2.

4. Verma M, Chhatwal J, George SM. Obesity and hypertension in children. Indian Pediatrics 1994;31:1065-9.

5. Ellenga Mbolla BF, Okoko AR, Mabiala Babela JR, et al. Prehypertension and Hypertension among Schoolchildren in Brazzaville, Congo. Int J Hypertens 2014;2014:803690.

6. Feber J, Ahmed M. Hypertension in children: new trends and challenges. Clin Sci 2010;119:151 61.

7. Urrutia-Rojas X, Egbuchunam CU, Bae S, et al. High blood pressure in school children: prevalence and risk factors. BMC Pediatrics 2006;6:32.

8. National High Blood Pressure Education Program Working Group on High Blood Pressure in Children and Adolescents. The fourth report on the diagnosis, evaluation, and treatment of high blood pressure in children and adolescents. Pediatrics 2004;114:555-76.

9. Luma GB, Roseann TS. Hypertension in Children and Adolescents - Am Fam Physician. Am Fam Physician 2006; 73:1558-68.

10. Riley M, Bluhm B. High Blood Pressure in Children and Adolescents. Am Fam Physician 2012;85:693-700.

11. Harrabi I, Belarbia A, Gaha R, et al. Epidemiology of hypertension among a population of school children in Sousse, Tunisia. Can J Cardiol 2006;22:212-6.

12. Ugwuja E, Ezenkwa US, Nwibo AN, et al. Prevalence and determinants of hypertension in an agrarian rural community in Southeast Nigeria. Ann Med Health Sci Res 2015;5:45.

13. Okoh BA, Alikor EA, Akani N. Prevalence of hypertension in primary school-children in Port Harcourt, Nigeria. Paediatr Int Child Health 2012;32:208-12.

14. Bissohong K. Profil Tensionnel des Enfants et Adolescents en milieu Scolaire dans la Ville de Bertoua. Université de Yaoundé I; 2014.

15. Fotso T. Etude de la Relation entre le Profil Pondéral et le Profil tensionnel dans une population scolaire de la vile de Yaoundé. Universite Des Montagnes; 2012. 
16. Samain NC. Prevalence and Risk Factors of Hypertension in Primary School Children in Buea Health District. University of Buea; 2015.

17. Mbankomo [Internet] 2018 [Cited 15 May 2018]. Available online: htttp://cvuc.cm/national/index.php/fr/ carte-communale/region-du-centre/115-association/carteadministrative/centre/mefou-et-akono/640-mankomo

18. Charan J, Biswas T. How to Calculate Sample Size for Different Study Designs in Medical Research. Indian J Psychol Med 2013;35:121-6.

19. Flynn JT, Kaelber DC, Baker-Smith CM, et al. Clinical Practice Guideline for Screening and Management of High Blood Pressure in Children and Adolescents. Pediatrics 2017;140:e20171904.

20. Kidy F, Rutebarika D, Lule SA, et al. Blood pressure in primary school children in Uganda:a cross-sectional survey. BMC Public Health 2014;14:1223.

21. Okpokowuruk FS, Akpan MU, Ikpeme EE. Prevalence of hypertension and prehypertension among children and adolescents in a semi-urban area of Uyo Metropolis, Nigeria. Pan Afr Med J 2017;28:303.

22. Muhihi AJ, Njelekela MA, Mpembeni RNM, et al. Elevated blood pressure among primary school children in Dar es salaam, Tanzania: prevalence and risk factors. BMC Pediatrics 2018;18:54.

23. Sabapathy S, Nagaraju BA, Bhanuprakash CN. Prevalence of childhood hypertension and pre-hypertension in school going children of Bangalore rural district: a cross sectional study. Int J Contemp Pediatr 2017;4:1701-4.

24. Manoja KD, Bhatia V, Anupam S. Prevalence of hypertension in urban school children aged 5 to 10 years in North India. Int J Contemp Pediatr 2017;4:2055-9.

Cite this article as: Chelo D, Mah EM, Chiabi EN, Chiabi A, Koki Ndombo PO, Kingue S, Obama MT. Prevalence and factors associated with hypertension in primary school children, in the centre region of Cameroon. Transl Pediatr 2019;8(5):391397. doi: $10.21037 /$ tp.2019.03.02
25. Sadoh WE, Omuemu VO, Sadoh AE, et al. Blood pressure percentiles in a group of Nigerian school age children. Niger J Paed 2014;41:223-8.

26. Kagura J, Adair LS, Musa MG, et al. Blood pressure tracking in urban black South African children: birth to twenty cohort. BMC Pediatr 2015;15:78.

27. Kanciruk M, Andrews JW, Donnon T. Family history of obesity and risk of childhood overweight and obesity: A meta-analysis. International Journal of Psychological and Behavioural Sciences 2014;8. Available online: waset.org/ abstracts/4316

28. Arun DJ, Kavinilavu R. A study of risk factors associated with hypertension among the school going children in Puducherry. Int J Community Med Public Health 2018;5:764-8.

29. Sorof J, Daniels S. Obesity Hypertension in Children A Problem of Epidemic Proportions. Hypertension [Internet] 2002 [cited 20 February 2018]. Available online: http://www.hypertensionaha.org

30. Edstedt Bonamy AK, Mohlkert LA, Hallberg J, et al. Blood Pressure in 6-Year-Old Children Born Extremely Preterm. J Am Heart Assoc 2017;6:e005858.

31. Poplawska K, Dudek K, Koziarz M, et al. PrematurityRelated Hypertension in Children and Adolescents. Int J Pediatr.2012;2012:537936.

32. Crump C, Winkleby MA, Sundquist K, et al. Risk of Hypertension Among Young Adults Who Were Born Preterm: A Swedish National Study of 636,000 Births. Am J Epidemiol 2011;173:797-803.

33. Norman M. Preterm birth - an emerging risk factor for adult hypertension? Semin Perinatol 2010;34:183-7. 